\title{
Postmenopozal Osteoporozlu Kadınlarda Torakal ve Lumbal Bölgenin Eğrilikleri İle Osteoporoz Şiddeti Arasındaki İlişkinin İncelenmesi
}

Investigation of the Relationship Between the Curvatures of the Thoracic and Lumbar Region and the Severity of Osteoporosis in Postmenopausal Women with Osteoporosis

Öznur BÜYÜKTURAN', Buket BÜYÜKTURAN ${ }^{1}$, Fatmanur Aybala Meral KOÇAK ${ }^{2}$

${ }^{1}$ Yrd. Doç. Dr. Ahi Evran Üniversitesi, Fizik Tedavi ve Rehabilitasyon Yüksek Okulu, Kırşehir.

${ }^{2}$ Yrd. Doç. Dr. Ahi Evran Üniversitesi, Tıp Fakültesi Fiziksel Tıp ve Rehabilitasyon AD., Kırşehir.

öz

\begin{abstract}
Amaç: Bu çalışma, postmenopozal osteoporozlu kadınlarda torakal ve lumbal bölgenin eğriliklerinin kemik mineral yoğunluğu (KMY) ile ilişkisini incelemek amacıyla planlanmıştır. Gereç ve Yöntem: Çalışmaya 62 postmenopozal osteoporozlu olgu dahil edilmiştir. Çalışmaya katılan bireylerin sosyo-demografik bilgileri kaydedilmiş ve sırt ağrısı, KMY, torakal ve lumbal bölge eğrilikleri değerlendirilmiştir. Sonuçlar: Olguların yaş ortalaması $63,33 \pm 5,67$ yıl olarak bulunmuştur. Çalışmanın sonuçlarına göre birbirleriyle korelasyon gösteren parametreler sırasıyla; yaş ile lumbal lordoz açısı ve lumbal bölgenin ekstansiyon açısı; VKI ile lumbal bölgenin fleksiyon açısı; kııık sayısı ile torakal bölgenin fleksiyon-ekstansiyon açı farkı; sırt ağıısı ile lumbal lordoz açısı, torakal ekstansiyon açısı ve torakal fleksiyon-ekstansiyon açı farkı; femurdan yapılan KMY ile lumbal bölgenin fleksiyon açısı olarak tespit edilmiştir $(p<0,05)$.Tartışma: Post-menopozal osteoporozlu kadınlarda sagital postürün bazı değerleri ile yaş, VKi, kırık sayısı, sırt ağıısı ve femoral t skoru arasında istatistiksel ilişki belirlenmişken, lomber $t$ skoru ile herhangi bir ilişki tespit edilmemiştir. Bu alanda daha fazla vaka ile yapılan daha kapsamlı ve ileri analizleri içeren çalışmalara intiyaç vardır.
\end{abstract}

Anahtar Kelimeler: Osteoporoz; Kemik Mineral Yoğunluğu; Kifoz; Lordoz.

\section{ABSTRACT}

Purpose: This study was planned to investigate the relationship between the curvatures of thoracal and lumbar region and bone mineral density (BMD) in women with postmenopausal osteoporosis. Material and Methods: Sixty-two individuals with postmenopausal osteoporosis were included in the study. Sociodemographic information of the subjects participating in the study was recorded and back pain, bone mineral density and curvatures of thoracal and lumbar region were evaluated. Results: Mean age of individuals were found as $63.33 \pm 5.67$ years. According to the results of the study; the parameters correlating with each other; age and lumbar lordosis, extension angle of lumbar region; BMI and flexion angle of lumbar region; number of fracture and angle-difference of flexion-extension of thoracic region; back pain and lumbar lordosis, thoracic extension angle, angle-difference of flexion-extension of thoracic; femoral BMD and lumbar region flexion angle were determined, respectively $(p<0.05)$. Discussion: Although statistically significant relationships were determined between some values of sagittal posture and age, BMI, number of fractures, back pain, and femoral $t$ score, no correlation was detected with lomber $\mathrm{t}$ score. In this issue, there is a need for more comprehensive studies which includes further analysis and more cases.

Key Words: Osteoporosis; Bone Density; Kyphosis; Lordosis. 
Osteoporoz kemik yoğunluğunda azalma ve kemik dokusunun mikro yapısında bozulma ile karakterize metabolik bir kemik hastalığıdır (Kling, Clarke ve Sandhu, 2014; Leidig-Bruckner, Minne, Schlaich ve ark, 1997). Osteoporozun kısa ve uzun dönem sonuçları arasında; mortalite, ağrı, fiziksel yetersizlik, yaşam kalitesinde bozulma, tedavi maliyetinde ve kırık oluşumu riskinde artış bulunmaktadır (Geusens, 2008; Lane, 2006; Kanis, Burlet, Cooper ve ark, 2008).

Osteoporoz, menopozal dönemdeki kadınlarda sıkça görülen kas iskelet sistemi problemlerindendir (Geusens, 2008). Yaşlanma ve osteoporoz varlığına bağlı olarak kas-iskelet sisteminde görülen en önemli değişikliklerden birisi ise postüral deformitelerdir (Ettinger, Black, Palermo ve ark, 1994; Culham, Jimenez ve King, 1994). Postüral değişiklikler osteoporozlu olgularda düşme, denge problemleri ve vertebral kırık gibi komplikasyonlara neden olabilmektedir (Cook, 2003). Postüral deformitelerin osteoporozda vertebral kırık sayısına, şiddetine ve yerine göre birçok farklı çeşitleri vardır (üst ve alt torakal bölge, torakolumbal bölge veya lumbal bölge.) (Miyakoshi, Itoi, Kobayashi ve ark, 2003). Satoh ve arkadaşları osteoporotik deformiteleri, torakal ve lumbal eğrilikleri temel alarak beş grup altında sınıflandırmıştır. Birincisi; spinal eğriliklerde belirgin bir değişiklik olmaksızın normal bir postürdür. İkincisi; artmış torakal kifoz ve normal lumbal lordozdur. Üçüncüsü; torakal kifoz ve lumbal lordozda artıştır. Dördüncüsü; torakal bölgeden lumbal bölgeye uzanan geniş bir kifoz ve beşincisi; düz torakal omurga ile lumbal bölgeye lokalize olmuş kifozdur. Bu postüral deformiteler omurgayı destekleyen yapılarda anormal stres oluşturmaktadır ve bu durum ayaktayken, yürürken ve günlük yaşam aktiviteleri esnasında sırt ağrısına neden olmaktadır (Satoh, Kasama, Itoi ve ark, 1988).

Osteoporozlu bireylerde görülen en belirgin deformite torakal kifozdur (Ettinger ve ark, 1994; Culham ve ark, 1994). Torakal kifoz oluşumu sonrasında spinal bölgenin bu deformiteyi dengelemek için ayakta durma pozisyonunda genel olarak lumbal bölgede, sakroiliak eklemlerde, kalçada ve diz eklemlerinde zorlanmaya yol açmakta ve torakal kifozla beraber lumbal lordozda artış görülmektedir. Bunun sonucunda da postüral deformiteler ortaya çıkmaktadır (Miyakoshi ve ark, 2003).

Postmenopozal osteoporozun bireylerde bazı biyomekanik değişikliklere sebep olduğu bilinmektedir. Ancak bu değişiklikler daha çok appendiküler iskelet kemiklerine, vertebralara ait kırıklar veya kemik kütlesindeki değişiklikler ile ilişkilidir (Myers ve Wilson, 1997; Neer, Arnaud, Zanchetta, ve ark, 2001). Ancak, osteoporozlu birey sayısının artmasına (Pınar, Pınar, Doğan ve ark, 2009) rağmen postüral deformitelerin osteoporozun şiddetiyle ilişkisini inceleyen çalışma sayısı sınırlıdır (Pfeifer, Begerow, ve Minne, 2004; Pfeifer, Kohlwey, Begerow ve ark, 2011). Bu çalışma, postmenopozal osteoporozlu kadınlarda torakal ve lumbal bölgenin eğriliklerinin yaş, vücut kütle indeksi (VKI), kırık öyküsü, sırt ağrısı ve kemik mineral yoğunluğu (KMY) ile ilişkisini incelemek amacıyla planlanmıştır.

\section{GEREÇ VE YÖNTEM}

Çalışmaya Mart 2016-Ekim 2016 tarihleri arasında, Ahi Evran Üniversitesi, Fizik Tedavi ve Rehabilitasyon Kliniğine başvuran, Dünya Sağlık Örgütü'nün osteoporoz (Baim, Binkley, Bilezikian ve ark, 2008) kriterlerine göre (kemik dansitesi femur boynu, femur total veya lomber 1-4 T skoru $<-2,5$ ) osteoporoz tanısı alan 40-75 yaş arası 62 postmenopozal osteoporozlu kadın olgu dahil edilmiştir. Çalışmaya dahil edilme kriterleri: menopoz tanısı almış olmak, Dünya Sağlık Örgütü kriterlerine göre osteoporoz tanısı almış olmak, bağımsız olarak ayakta durabilmek, spinal fleksiyon ve ekstansiyon hareketini yapabilmektir. Çalışmanın dışlanma kriterleri ise; herhangi devam eden bir ortopedik ya da nörolojik hastalık varlığı, ayakta durmaya ve yük vermeye engel alt ekstremite ağrısı, bilişsel fonksiyon bozukluğu, vertebra cerrahisi geçirmiş olmak, osteoporoz dişı metabolik kemik hastalığı varlığı, görme veya işitmeyle ilgili herhangi bir problemin olmasıdır. $\mathrm{Bu}$ çalışma yerel etik kurul (Tarih: 21.03.2017; Karar No: 2017-06/48) tarafından onaylanmış ve Helsinki Deklerasyonuna uygun olarak yapılmıştır. Çalışmaya katılan olgulardan yazılı ve sözlü onam alınmıştır.

Değerlendirmeler: Çalışmaya dahil edilen olguların değerlendirmeleri sırasıyla şu şekilde yapılmıştır;

KMY Taraması: Olguların KMY ölçümleri lomber vertebralardan ve proksimal femurdan DEXA cihazı ile değerlendirilmiştir. Çalışmada DEXA cihazıyla değerlendirilen KMY ölçümü için lomber ve femur boynu $T$ skorları değerlendirmeye alınmıştır (Baim ve ark, 2008; Erselcan, Özen, Yüksel ve ark, 2009).

Sosyo-Demografik Bilgiler: Çalışmaya alınan 
olguların yaş, VKi $\left(\mathrm{kg} / \mathrm{m}^{2}\right)$, osteoporoz tanı süresi, kırık öyküsü kaydedilmiştir.

Ağrı: Olguların sırt ağrısı şiddeti visüel analog skalası (VAS) ile değerlendirilmiştir. Son 4 haftadaki ortalama ağrı şiddeti sorgulanmıştır. Olgulardan ağrılarının şiddetini $10 \mathrm{~cm}$ 'lik bir çizgi üzerinde; 0 (hiç ağrı yok) ile 10 (dayanılmaz ağrı) arasında derecelendirerek işaretlemesi istenmiş ve sonuçlar cm cinsinden kaydedilmiştir (Akyol, Atmaca, Durmuş ve ark, 2011).

Sagital Postür: Olguların sagital postürü Spinal Mouse (SM) (Idiag, Volkerswill, Switzerland) cihazı kullanılarak değerlendirildi. SM yüzeysel olarak omurganın eğriliklerini ve mobilitesini ölçen, bilgisayar destekli, noninvaziv bir cihazdır. Değerlendirme öncesi tüm olguların servikal 7 ve sakral 3 vertebraları deneyimli bir fizyoterapist tarafından palpe edilmiş ve işaretlenmiştir. Olgular değerlendirilirken sırtı görülecek şekilde ayakta en rahat ettiği pozisyonda durması istenmiştir. SM cihazı servikal 7. vertebraya yerleştirilmiş ve üzerindeki tuşa basılarak kayıt başlatılmışıı. Cihaz tekerlekleri aracılığıyla işaretlenen spinöz çıkıntılar hizası boyunca servikal 7 . vertebradan sakral 3 . vertebraya kadar deri üzerinden hareket ettirilerek sakral 3 hizasına gelindikten sonra cihaz üzerindeki tuşa tekrar basılarak kayıt tamamlanmştır. Cihaz kayıt esnasında içerisindeki sensör aracılığıyla omurgaya ait açıları kablosuz bağlantı aracılığı ile kendi yazılımının bulunduğu bilgisayara aktarmıştır. Ayakta yapılan ölçümler gövde nötral dik duruşta, maksimum fleksiyon ve ekstansiyon pozisyonlarında yapılmıştır. SM cihazından elde edilen dik duruşta torakal kifoz ve lumbal lordoz açıları, maksimum fleksiyon ve ekstansiyon ölçümünde ise torakal, lumbal, sakral ve inklinasyon açılarının fleksiyon, ekstansyion ve bu değerlerin farkı kaydedilmiştir (Post ve Leferink, 2004).

Tablo 1. Olguların sosyo-demografik özellikleri

\section{İstatistiksel Analiz}

Çalışma sonunda elde edilen verilerin istatistiksel analizi için SPSS v. 21.0 (SPSS, Inc, Chicago, IL, USA) kullanıldı. Verilerin normal dağılıma uyup uymadığı Shapiro-Wilk testiyle değerlendirilmiş ve tüm verilerin normal dağılıma uyduğu belirlenmiştir. Tanımlayıcı istatistikler sürekli değişkenler için ortalama sstandart sapma biçiminde verilmiştir. Torakal ve lumbal bölge eğrilikleri ile yaş, VKİ, geçirilmiş kırık sayısı, sırt ağrısı, KMY (lumbal ve femur) arasındaki ilişkinin belirlenmesinde Pearson Korelasyon Testi kullanılmıştır. $\quad p<0,05$ seviyesinde sonuçlar istatistiksel olarak anlamlı kabul edilmiştir.

\section{SONUÇLAR}

Çalışmaya yaş ortalaması 63,33ะ5,67 yıl olan 62 post-menopozal osteoporozu olan kadın olgu çalışmaya dahil edilmiştir. Olguların sosyodemografik ve KMY ölçüm sonuçları, geçirilmiş kırık sayıları ve sırt ağrısı bilgileri Tablo 1'de gösterilmiştir.

Çalışmanın sonuçlarına göre yaş ile lumbal lordoz ( $r: 0,361 ; p: 0,050)$ ve lumbal bölgenin ekstansiyon açısı ( $r$ : 0,405; p:0,027) ile pozitif yönde anlamlı bir ilişki olduğu, VKi ile lumbal bölgenin fleksiyon açısı arasında negatif yönde anlamlı bir ilişki olduğu (r:-0,359; p:0,046), kırık öyküsü ile torakal bölgenin fleksiyon-ekstansiyon açı farkı arasında pozitif yönde anlamlı bir ilişki olduğu (r: 0,386; p:0,028), sırt ağrısı ile lumbal lordoz ( $r: 0,502 ; p: 0,010)$ ve torakal bölgenin fleksiyon-ekstansiyon açı farkı (r:0,471; p:0,003) ile pozitif yönde, torakal ekstansiyon ile negatif yönde anlamlı bir ilişki olduğu (r:-0,388; p:0,031), femoral KMY ile lumbal bölgenin fleksiyon açısı ile negatif yönde anlamlı bir ilişki olduğu (r:-0,422; p: 0,036) belirlenmiştir (Tablo 2 ).

\begin{tabular}{lllll}
\hline & Ortalama & Standart sapma & Minimum & Maksimum \\
\hline Yaş & 63,33 & 5,67 & 50 & 73 \\
\hline VKİ & 32,07 & 4,93 & 24,50 & 49,00 \\
\hline Lomber KMY & $-2,88$ & 0,44 & $-4,2$ & $-2,5$ \\
\hline Femur KMY & $-0,37$ & 1,12 & $-2,4$ & 2,3 \\
\hline Sirt ă̆risı & 4,21 & 2,66 & 1,0 & 6,71 \\
\hline Kırık Sayısı & 1,46 & 0,41 & 1,0 & 4,0 \\
\hline
\end{tabular}


Tablo 2. Torakal ve lumbal bölge eğrilikleri ile yaş, VKİ, kırık sayısı, sırt ağrısı, lomber ve femoral KMY verileri arasındaki ilişki

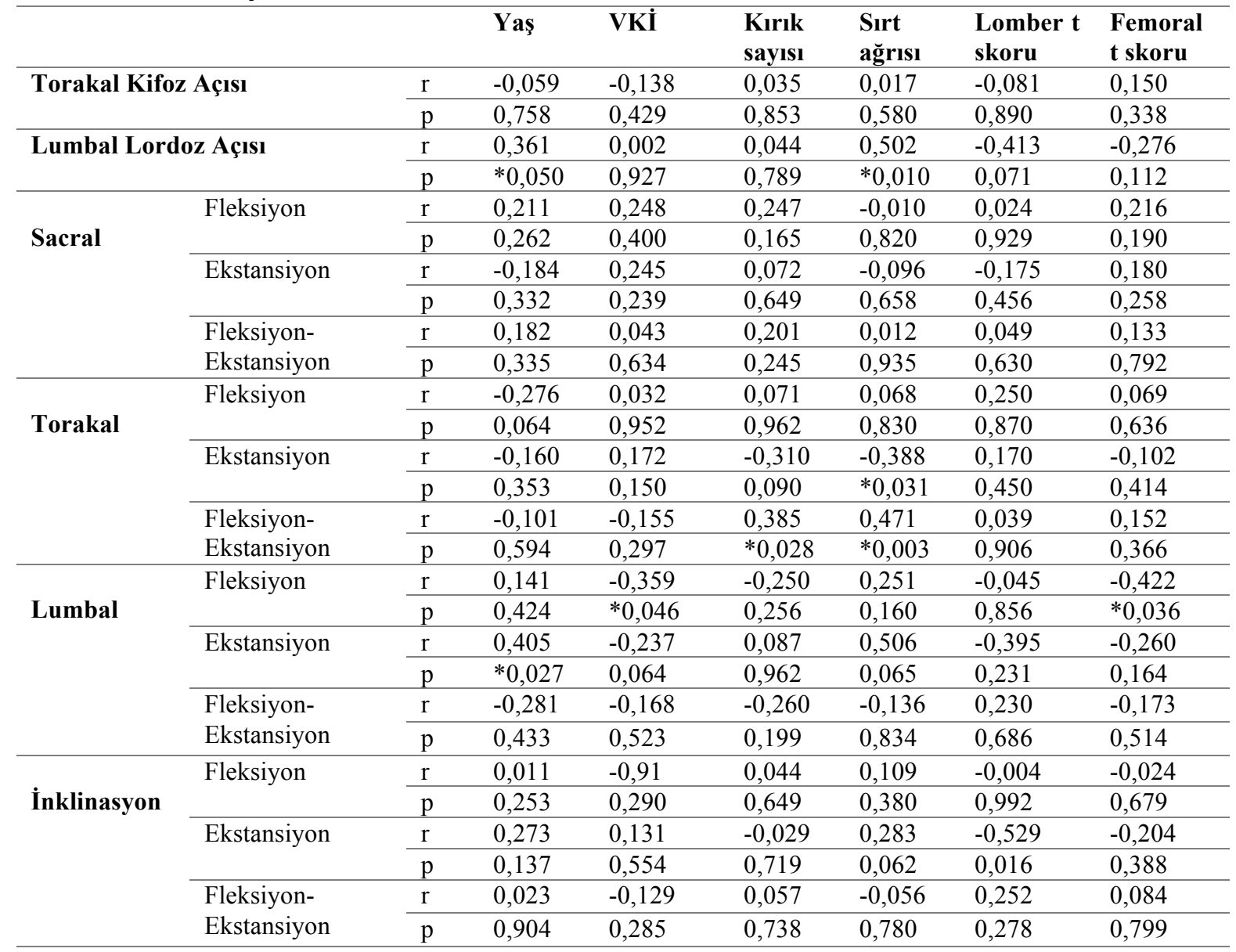

\section{TARTIŞMA}

Bu çalışmanın sonucu olarak yaş ile lumbal lordoz ve lumbal bölgenin ekstansiyon açısının, VKI ile lumbal bölgenin fleksiyon açısının, kırık öyküsü ile torakal bölgenin fleksiyon-ekstansiyon açısının, sırt ağrısı ile lumbal lordozun, torakal ekstansiyonun ve fleksiyon-ekstansiyon açısının, femurdan yapılan KMY taraması ile lumbal bölgenin fleksiyon açısının ilişkili olduğu belirlenmiştir.

$\mathrm{Bu}$ çalışmada postmenopozal osteoporozlu bireylerde yaşın lumbal lordozla ve lumbal bölgenin ekstansiyon açısıyla pozitif yönde anlamlı bir ilişki olduğu belirlenmiştir. Krause ve arkadaşları yaptıkları çalışmada yaşın artmasıyla birlikte torakal kifozun, lumbal lordozun ve gövde inklinasyon açısının artmasının ilişkili olduğunu göstermişlerdir (Krause, Breer, Mohrmann ve ark, 2013). Bu çalışmada yaşın sadece lumbal bölge eğrilikleriyle ilişkili olduğu görülmektedir. Bu konuyla ilgili daha fazla olgu sayısına ve bu olguların yaşlarının gruplandırılarak torakal ve lumbal bölge eğrilikleriyle ilişkisine bakılmasıyla daha iyi bir sonuç elde edileceği düşünülmektedir.

Postmenopozal dönemdeki kadınlarda menstural siklusun sona ermesi, bazal metabolizma hızının yavaşlaması ve sedanter yaşam sonucunda VKI'de artış görülmektedir (Aslan ve Attila, 2002). VKi'deki artış sonucunda postüral deformitelerin oluştuğu görülmekte ve özelikle torakal kifozda artış görüldüğü belirtilmektedir (Canbay, Doğru, Katayıfçı ve ark, 2016). Çalışmamızda VKi ile lumbal bölgenin fleksiyon açısı ile negatif yönde bir ilişki olduğu görülmüştür. Yani VKi arttıkça lumbal bölgenin fleksiyon açısında azalma olacağı düşünülmektedir. Ostrowska yaptığı çalışmada VKI ile lumbal lordoz ve lumbosakral açı ile ilişkili olduğunu belirtmişlerdir (Ostrowska, 2006). Bu yönüyle çalışmamız literatür ile uyumludur.

Postmenopozol osteoporozlu bireylerin yaşadıkları kırık sayısı ile sadece torakal bölgenin fleksiyon-ekstansiyon açı farkı arasında pozitif yönde bir ilişki olduğu bu çalışmada gözlenmiştir. Krause ve arkadaşları, torakal ve lumbal bölgelerdeki vertebral kırıkların torakal kifozda 
artışa neden olduğu, lumbal lordozu azalttığı ve gövde inklinasyon açısını arttırdığını belirtmişlerdir (Krause ve ark, 2013). Kobayashi ve arkadaşları spinal eğriliklerin, özellikle lumbal omurgada, dejeneratif modifikasyonlar sırasında azalma eğilimi gösterdiğini açıklamışlardır (Kobayashi, Takeda, Atsuta ve ark, 2008). Bu çalışmaya dahil edilen olguların kırık öyküleri incelendiğinde literatür ile uyumlu olarak torakal bölge kırıklarının daha yoğun olduğu görülmüştür (Cummings ve Melton, 2002; Oleksik, Lips, Dawson ve ark, 2000). Çalışmamızın sonucunda kırık öyküsünün sadece torakal bölgenin fleksiyonekstansiyon açı farkıyla ilişkili çıkmasının nedeni olarak vertebral kırıkların özellikle torakal bölgeyi etkilemesi olduğu düşünülebilir.

Sırt ağrısı olan osteoporozlu bireylerde VAS değerleri, torakal bölgenin fleksiyon-ekstansiyon açısıyla ve lumbal lordozla pozitif yönde, torakal bölgenin ekstansiyon açısıyla ise negatif yönde ilişkili olduğu bu çalışmanın sonuçlarına göre tespit edilmiştir. Osteoporozlu bireylerde ağrı ve yetersizlik sıklıkla görülmektedir (Cummings ve Melton, 2002; Oleksik ve ark, 2000). Ancak, osteoporozlu bireyler bu durumun osteoporozdan kaynaklandığını düşünmemektedirler (Ryan, Blake, Herd ve ark, 1994). Bununla birlikte klinik olarak, sırt ağrısı ile kifozun derecesi arasında bir ilişki olduğu da söylenmektedir (Ryan ve ark, 1994). Osteoporoz her ne kadar ağrı oluşturan bir patoloji değilse de, komorbiditeleri ağrıya sebep olabilir (Paolucci, Morone, losa ve ark, 2014). Bu çalışmada ağrı ile lordoz ve kifoz arasında ilişki bulunması, olguların osteoporozun komorbiditeleri sebebiyle yaşadığı ağrı sonucu tespit edilmiş olduğu düşünülmektedir.

Mika ve arkadaşları, kemik kaybı olan osteoporozlu bireylerde yaptıkları çalışmada sırt ekstansör kasların kas kuvvetiyle torakal kifoz arasında ilişki olduğunu, fakat torakal kifoz deformitesi ile kemik mineral kaybı arasında önemli bir ilişki bulmadıklarını belirtmişlerdir (Mika, Unnithan ve Mika, 2005). Ostrowska, osteoporozu olan bayanlarda kifotik postürün KMY ile ilişkisini değerlendirmişlerdir. Çalışmalarında lumbal ve torakal bölgenin eğriliklerini fotogrametri ile değerlendirmişlerdir. Yaptıkları çalışma sonucunda spinal eğriliklerle KMY arasında önemli bir korelasyon bulduklarını belirtmişlerdir (Ostrowska, 2006). Literatürde KMY ile torakal ve lumbal bölge eğrilikleri arasında ilişkisi olduğunu söyleyen çalışmaların yanında ilişkili olmadığını belirten çalışmalarda bulunmaktadır (Mika ve ark, 2005;
Ostrowska, 2006). Bu çalışmada KMY ölçümleri lumbal vertebradan ve proksimal femurdan yapılmıştır. Çalışmanın sonunda lomber T skoru ile torakal ve lumbal bölge eğrilikleri arasında bir ilişki bulunmamıştır ve femur boynu $\mathrm{T}$ skoru ile sadece lumbal bölgenin fleksiyon açısı arasında negatif bir ilişki olduğu belirlenmiştir.

Literatür incelendiğinde torakal ve lumbal bölge eğrilikleri ile yaş, VKI, sırt ağrısı, kırık öyküsü ve KMY arasındaki ilişkiyi değerlendiren çalışmalar bulunmaktadır (Canbay ve ark, 2016; Krause ve ark, 2013; Mika ve ark, 2005; Ostrowska, 2006; Ryan ve ark, 1994). Bu çalışmalar omurga eğrilikleri ile yaş, VKi, kırık öyküsü ve sırt ağrısı arasındaki ilişkini olduğunu belirtmişlerdir. Fakat omurga eğrilikleri ile KMY arasında ilişkili olduğunu belirten çalışmaların yanında ilişkili olmadığını gösteren çalışmalarda bulunmaktadır (Mika ve ark, 2005; Ostrowska, 2006). Bu çalışmanın sonuçlarına göre spinal eğriliklerin bazı parametreleri ile yaş, VKI, kırık öyküsü, sırt ağrısı ve femoral KMY arasında, ilişki görülmüş, fakat genel olarak verilerin çoğunda anlamlı düzeyde ilişki görülmemiştir.

$\mathrm{Bu}$ çalışmanın bazı limitasyonlarından söz etmek gerekir. Birincisi, SM cihazıyla değerlendirilen spinal deformiteler sınıflandırılmamıştır. Yani, çalışmamızın popülasyonunu oluşturan bireyler için aynı yaş grubunda yer alan bireylerde belirlenen normatif kifoz ve/veya lordoz değerlerine göre sınıflandırma yapılabilirdi. İkinci, osteoporuzun tanı konulduğu yaş dekatına göre ve tanı süresine göre olguları gruplara ayrılarak daha kapsamlı değerlendirme yapılabilir ve post-menopozal osteoporozu olmayan bireyler kontrol grubu olarak çalışmaya dahil edilebilirdi. Üçüncü; olguların denge ve/veya düşme riski ile ilgili bir parametre çalışmada değerlendirilebilirdi.

Sonuç olarak; post-menopozal kadınlarda sagital postürün bazı değerleri ile yaş, VKİ, geçirilmiş kırık sayısı, sırt ağrısı ve femoral t skoru arasında istatistiksel ilişki bulunmuşken, lomber $t$ skoru ile herhangi bir ilişki bulunmamıştır. Bu alanda daha fazla vaka ve kontrol grubu kullanılarak yapılan daha kapsamlı ve ileri analizleri içeren çalışmalara intiyaç vardır.

\section{Kaynaklar}

Akyol, Y., Atmaca, A., Durmuş, D., Ulus, Y., Tander, B., \& Alaylı, G. (2011). Şiddetli postmenopozal osteoporozlu hastalarda teriparatid tedavisinin ağrı, yaşam kalitesi, depresyon ve biyokimyasal parametreler üzerine etkisi: 
erken dönem sonuçlar. Turk Fiz Tıp Rehab Derg, 57, 134-8.

Aslan, D., \& Attila, S. (2002). Önemli bir sağlık sorunu: şişmanlık. Sürekli Tıp Eğitim Dergisi (Sted), 11(5), 169171.

Baim, S., Binkley, N., Bilezikian, J. P., Kendler, D. L., Hans, D. B., Lewiecki, E. M., \& et al. (2008). Official positions of the International Society for Clinical Densitometry and executive summary of the 2007 ISCD Position Development Conference. J of Clin Densitom, 11(1), 75-91.

Canbay, Ö., Doğru, E., Katayıfçı, N., Duman, F., Şahpolat, M., Kaya, İ., \& et al. (2016). Bir üniversite hastanesi çalışanlarında obezite görülme sıkığının ve beslenme alışkanlıklarının araştıııması. Medical Journal of Bakirkoy, 12(3), 129-135.

Cook, C. (2003). The relationship between posture and balance disturbances in women with osteoporosis. Phys Occup Ther Geriatr, 20(3-4), 37-49.

Culham, E. G., Jimenez, H. A., \& King, C. E. (1994). Thoracic kyphosis, rib mobility, and lung volumes in normal women and women with osteoporosis. Spine, 19(11), 1250-1255.

Cummings, S. R., \& Melton, L. J. (2002). Epidemiology and outcomes of osteoporotic fractures. The Lancet, 359(9319), 1761-1767.

Erselcan, T., Özen, A., Yüksel, D., Altun, G. D., Öztürk, E., \& Balcı, T. A. (2009). Kemik mineral yoğunluğu ölçümü uygulama kılavuzu. Turk J Nucl Med, 18(1), 31-40.

Ettinger, B., Black, D. M., Palermo, L., Nevitt, M. C., Melnikoff, S., \& Cummings, S. R. (1994). Kyphosis in older women and its relation to back pain, disability and osteopenia: the study of osteoporotic fractures. Osteoporos Int, 4(1), 55-60.

Geusens, P. (2008). Osteoporosis: clinical features. Minerva Med, 99(2), 167-175.

Kling, J. M., Clarke, B. L., \& Sandhu, N. P. (2014). Osteoporosis prevention, screening, and treatment: a review. J Womens Health (Larchmt), 23(7), 563-572.

Kanis, J. A., Burlet, N., Cooper, C., Delmas, P. D., Reginster, J. Y., Borgstrom, F., et al. (2008). European guidance for the diagnosis and management of osteoporosis in postmenopausal women. Osteoporos Int, 19(4), 399428.

Kobayashi, T., Takeda, N., Atsuta, Y., \& Matsuno, T. (2008). Flattening of sagittal spinal curvature as a predictor of vertebral fracture. Osteoporos Int, 19(1), 65-69.

Krause, M., Breer, S., Mohrmann, B., Vettorazzi, E., Marshall, R. P., Amling, M., et al. (2013). Influence of non-traumatic thoracic and lumbar vertebral fractures on sagittal spine alignment assessed by radiation-free spinometry. Osteoporos Int, 24(6), 1859-1868.

Lane, N. E. (2006). Epidemiology, etiology, and diagnosis of osteoporosis. Am J Obstet Gynecol, 194(2), 3-11.

Leidig-Bruckner, G., Minne, H. W., Schlaich, C., Wagner, G., Scheidt-Nave, C., Bruckner, \& et al. (1997). Clinical grading of spinal osteoporosis: quality of life components and spinal deformity in women with chronic low back pain and women with vertebral osteoporosis. J Bone Miner Res, 12(4), 663-675.

Mika, A., Unnithan, V. B., \& Mika, P. (2005). Differences in thoracic kyphosis and in back muscle strength in women with bone loss due to osteoporosis. Spine, 30(2), 241-246.

Miyakoshi, N., Itoi, E., Kobayashi, M., \& Kodama, H. (2003). Impact of postural deformities and spinal mobility on quality of life in postmenopausal osteoporosis. Osteoporos Int, 14(12), 1007-1012.

Myers, E. R., \& Wilson, S. E. (1997). Biomechanics of osteoporosis and vertebral fracture. Spine, 22(24), 2531.

Neer, R. M., Arnaud, C. D., Zanchetta, J. R., Prince, R., Gaich, G. A., Reginster, J. Y., \& et al. (2001). Effect of parathyroid hormone (1-34) on fractures and bone mineral density in postmenopausal women with osteoporosis. N Engl J Med, 344(19), 1434-1441.

Oleksik, A., Lips, P., Dawson, A., Minshall, M. E., Shen, W., Cooper, C., \& et al. (2000). Health-related quality of life in postmenopausal women with low bmd with or without prevalent vertebral fractures. J Bone Miner Res, 15(7), 1384-1392

Ostrowska, B. (2006). The shape of anterior-posterior spinal curvature in post-menopausal women with osteoporosis. Ortop Traumatol Rehabil, 8(5), 537-542.

Paolucci, T., Morone, G., Iosa, M., Grasso, M. R., Buzi, E., Zangrando, F., \& et al. (2014). Efficacy of groupadapted physical exercises in reducing back pain in women with postmenopausal osteoporosis. Aging Clin Exp Res, 26(4), 395-402

Pfeifer, M., Begerow, B., \& Minne, H. W. (2004). Effects of a new spinal orthosis on posture, trunk strength, and quality of life in women with postmenopausal osteoporosis: a randomized trial. Am J Phys Med Rehabil, 83(3), 177-186.

Pfeifer, M., Kohlwey, L., Begerow, B., \& Minne, H. W. (2011). Effects of two newly developed spinal orthoses on trunk muscle strength, posture, and quality-of-life in women with postmenopausal osteoporosis: a randomized trial. Am J Phys Med Rehabil, 90(10), 805-815

Pınar, G., Pınar, T., Dogan, N., Karahan, A., Algıer, L., Abbasoglu, A., et al. (2009). Kırk beş yaş ve üstü kadınlarda osteoporoz risk faktörleri. Dicle Tıp Dergisi, 36(4), 258-266.

Post, R. B., \& Leferink, V. J. M. (2004). Spinal mobility: sagittal range of motion measured with the Spinal Mouse, a new non-invasive device. Arch Orthop Trauma Surg, 124(3), 187-192.

Ryan, P. J., Blake, G., Herd, R., \& Fogelman, I. (1994). A clinical profile of back pain and disability in patients with spinal osteoporosis. Bone, 15(1), 27-30.

Satoh, K. Kasama, F., Itoi, E., Tanuma, M., \& Wakamatsu, E. (1988). Clinical features of spinal osteoporosis: spinal deformity and pertinent back pain. Contemp Orthop, 16, 23-30. 